\title{
A CULTURA ORGAZICIONAL E O(S) PODERE(S) DA HISTÓRIA NA ESTRUTURAÇÃO DA IDENTIDADE DA EMPRESA
}

António Rafael Amaro

\section{INTRODUÇÃO}

O pior contributo - seja em que perspectiva for - que neste momento se pode dar ao debate sobre a vertente cultural das organizações é escamotear a sua dimensão ideológica e considerar a emergência da cultura de empresa como neutra. Será talvez útil recordar que esta não é a primeira vez, nem por certo a última, que as teorias sobre as organizações recorrem a metáforas como modelos de compreensão e explicação. Se as teorias, hoje emergentes, se socorrem da metáfora cultural - considerando, portanto, as organizações culturas —, já anteriormente o mesmo se verificou com outras teorias que viam as empresas, como refere Jorge Vala, «metaforicamente ora como máquinas (lembremos os primeiros estudos no interior do paradigma da organização científica do trabalho), ora como organismos (metáfora subjacente às teorias sistémicas sobre as organizações), ora como cérebros (teorias da decisão e do processamento da informação aplicadas às organizações), etc.» (J. Vala et al.,1988: 663).

Não perder de vista esta dimensão diacrónica e sincrónica, em relação às mudanças metafóricas das várias teorias sobre as organizações, é, em nosso entender, condição indispensável para que se não confunda a metáfora com a realidade. Evitando-se, assim, o perigo de deixar de encarar o conceito cultural como mais um modelo de análise da realidade envolvente às organizações - não obstante a forma surpreendente como ele foi aceite - , para se passar a ter sempre presente que, tal como aconteceu com as metáforas anteriores, esta também tem subjacente um determinado paradigma científico e ideológico. Aliás, isto nada tem de negativo nem de surpreendente, pois é sabido como a ciência em geral mantém uma relação profunda com as ideologias. Importante, todavia, é ter-se consciência deste facto, não esquecendo que «o recurso ao conceito de cultura de empresa para descrever o que se passa dentro da empresa sob o ângulo das relações sociais não é neutro» (A. Beltran e M. Ruffat, 1991: 20) ${ }^{1}$. Ou seja: para o modelo interpretativo em causa, «A empresa não será mais — ou apenas — o teatro abs- 
tracto e imutável do drama sempre renovado da luta de classes, mas um lugar de vida que elabora pouco a pouco os seus usos e as suas regras, e segrega uma dinâmica que lhe é própria» (Idem). Significa isto que a utilização da metáfora cultural «corresponde a uma visão das relações sociais mais consensual» (Idem) e que pretende preencher aquilo que alguns autores denominam por «a regressão paralela da cultura patrimonial no seio do patronato e da cultura revolucionária no seio do assalariado ${ }^{2}$. Paradigma epistemológico e ideológico que, no entender de Henri Weber, abre «o espaço à renovação institucional da empresa - "as empresas de terceiro tipo" $»^{3}$.

Esta referência prévia à ideologia — que, necessariamente, se encontra subjacente a todo este movimento em torno da vertente cultural das organizações tem como objectivo tornar claro que qualquer reflexão, neste caso por parte dos historiadores, sobre o papel que a história (história da empresa e na empresa ) pode desempenhar nas organizações não deve deixar à margem duas importantes questões intimamente ligadas. A saber: o porquê da emergência das empresas como sistemas culturais e, sobretudo, a que se deve este crescente interesse, por parte das organizações, pela sua memória histórica enquanto estruturadora da sua identidade e mesmo como auxiliar preciosa das decisões, estratégias e/ou políticas empresariais.

Ninguém melhor que os historiadores poderá entender a pertinência desta reflexão, dado que nenhuma outra ciência está em melhores condições para entender a relação existente entre a conjuntura e o conhecimento produzido e, mais especificamente, ninguém melhor do que a história poderá ser tão sensível ao(s) poder(es) e ao papel da memória como elemento fundamental na estruturação da identidade de uma nação ou de um grupo. $\mathrm{E}$, talvez por isso, também ninguém melhor que os historiadores saberá como as leituras do passado - quer seja de uma nação, ou de um grupo -, ao fornecerem uma determinada explicação do processo histórico, acabam sempre por legitimar um determinado presente e um determinado futuro. Ou seja: a historiografia, o discurso histórico, quer seja sobre a sociedade em geral, quer seja sobre uma empresa, não é neutro. Tal como também não é inocente a importância crescente que se tem vindo a atribuir à memória, por parte dos vários poderes e, sobretudo, pelas organizações.

Queremos com isto dizer (não adianta continuar os preconceitos contra as ideologias) que a história - sobretudo a história na empresa - acaba sempre por ter uma função ideológica: «funcionando como toda a ideologia, escreveu B. Ramanantsoa, apontando o futuro portador de mitos, ela [história] pode ajudar a dar um sentido à acção colectiva, estruturando em particular a identidade da empresa (...)» ${ }^{4}$.

É evidente que a história não é ideologia, mas só terá a ganhar se tiver consciência de que o seu discurso sobre o passado da empresa, mesmo crítico e perto do "real", fixa uma maneira de ver o mundo, e que, deste modo, servirá, tal como na mão de outros poderes, para legitimar e dar sentido a uma determinada polí- 
tica ${ }^{5}$. De uma outra forma: qualquer reflexão sobre as produções simbólicas, ou sobre as fontes do poder na empresa, jamais poderá esquecer o papel ideológico que o discurso histórico tem. Pois, lembra mais uma vez B. Ramanantsoa, «uma das acções prioritárias (e muitas vezes ocultada) do dirigente é a de estruturar o universo da empresa, dar-lhe forma e sentido» e é «nesta perspectiva que a história e a sua escrita aparecem como fundamentais» ${ }^{6}$.

Esta leitura, sobre o papel da história na empresa, não deve ser entendida, nem nos parece que seja essa a intenção do autor que temos vindo a seguir, como uma denúncia de uma voluntária e consciente forma de manipulação da história ao serviço da empresa. Mas não deixa de ser uma chamada de atenção para todos os que, muitas vezes sem qualquer preparação como historiadores e quantas vezes ignorando a evolução metodológica e teórica da história, se dedicam a fazer o estudo das empresas de forma parcial e apologética sem o mínimo rigor científico. Pois, na opinião do autor citado, a maioria das empresas ainda hoje escrevem «a sua história nesta perspectiva»?

Incapaz, portanto, de fugir a esta ligação com a ideologia, será o papel da história negativo, numa perspectiva de uma gestão pela cultura não manipulatória? Evidentemente que não. Todas as organizações, logo após a sua fundação - haja ou não discurso escrito-, recorrem e apelam no seu dia-a-dia, nem sempre de forma consciente, para a sua dimensão histórica. Muitas das suas decisões e projectos são marcados por exemplos do passado, pela memória da empresa. Logo, o recurso à história, numa perspectiva científica, não deixa de ser natural se tivermos em consideração — o mesmo já aconteceu, como demonstrou Lévi-Strauss, nas sociedades ditas históricas ${ }^{8}-$ que a história tem a função (parece que positiva, a analisar pelo interesse crescente que as empresas mostram em conhecer a sua "verdadeira" história) de substituir uma memória mitológica, por uma outra memória histórica, mais crítica e problemática. Assim sendo, mesmo numa perspectiva manipuladora, uma memória mitológica não se apresenta menos "ideologizada", ou passível de ser manipulada, do que uma memória histórica, com a agravante de o mito fazer o seu percurso sinuoso sem conhecer autor - como se sabe é isto que melhor define o discurso mitológico —, o que não acontece com o discurso histórico que, para além de recorrente, responsabiliza sempre quem o produz.

Não sejamos portanto, adverte B. Ramanantsoa, «prisioneiros da conotação muitas vezes negativa atribuída ao termo "ideologia" - e em particular na empresa. A ideologia e a história têm um papel de reenviar os significados aos indivíduos que os querem receber, na medida em que sentem necessidade deles. É muito útil, para agir, ter uma visão coerente do mundo, da mesma maneira que cada um pode ter necessidade de um ideal (...). A ideologia e a história podem ter esta função de reenviar significados comuns, partilhados pelas diferentes pessoas da empresa»? 


\section{CULTO DA EMPRESA E IDEOLOGIA EMPRESARIAL}

A história e os historiadores em geral, apesar da proclamada necessidade de interdisciplinaridade, têm evidenciado, por vezes, uma indisfarçável (nem sempre admitida) dificuldade em acompanhar os movimentos de outras ciências sociais, ficando, muitas vezes, a sensação de andarem a reboque de problemáticas abertas por outras áreas do saber. $\mathrm{O}$ exemplo mais elucidativo, do que acabamos de referir, está na dificuldade que a história e os historiadores vêm demonstrando, em acompanhar os debates epistemológicos e teóricos (e mesmo os contributos bastante evidentes de outras ciências) - casos da antropologia, sociologia, psicologia etc. - no que concerne ao estudo e papel das organizações, sobretudo das organizações produtivas, na sociedade contemporânea. É verdade que em países como os E.U.A, Grã-Bretanha e França, para apenas citarmos os mais importantes, esta problemática não tem sido esquecida, mas está muito longe de ter um papel semelhante ao que detêm nas ciências sociais por nós anteriormente referidas. Isto, para já não falarmos de exemplos de países, como Portugal, onde pesem embora algumas poucas excepções - esta problemática está pouco mais que virgem. Os historiadores portugueses têm-se limitado, quando muito, a acompanhar alguns dos desenvolvimentos que nos chegam de outros países, sem que, até ao momento, se note qualquer impacto de registo na abordagem desta problemática. Saliente-se, a propósito, o que a este respeito referiu J. Amado Mendes, um dos poucos historiadores (diga-se em abono da verdade) que em Portugal pelo menos tanto quanto nos é dado saber - tem mostrado sensibilidade para esta questão: ${ }^{10}$ «Em Portugal, pesem embora os contributos já dados, muito há ainda a fazer. Além do mais, será do maior interesse — não só histórico como científico-cultural - promover um amplo debate e uma profunda reflexão sobre o assunto, tirando-se as devidas ilações das experiências levadas a cabo» ${ }^{11}$. Para este historiador há que caminhar na seguinte direcção: " por um lado, para a necessidade de incrementar uma nova e mais actualizada metodologia, na linha daquela que já começa a ser designada por "nova história das empresas"; por outro lado, para uma profícua inter-relação entre história e empresa, da qual ambas têm muito que aproveitar» ${ }^{12}$.

A verdade, porém, é que, seja qual for a perspectiva em que nos coloquemos, dois importantes fenómenos, a nosso ver interdependentes, marcaram o mundo empresarial neste final do século $\mathrm{XX}$, aos quais a história e os historiadores, pelas implicações teóricas, sociais e ideológicas a eles ligados, não podem permanecer indiferentes: a emergência da metáfora cultural em relação às organizações, por um lado, e a revalorização, aliada de uma crescente legitimação social, do papel da empresa e dos empresários nas sociedades contemporâneas, por outro.

A coincidência deste facto - sobretudo se pensarmos que assistimos, neste final de século, a um profundo vazio e a uma vincada crise de identidade, em 
certa medida, provocados pela ruptura clara com ideologias e modelos culturais até aqui dominantes - não é inocente. Paradoxalmente (ou talvez não), não deve deixar de merecer uma séria reflexão o facto de a empresa e os empresários precisamente numa altura em que grande parte das tradicionais utopias e dos velhos mitos entram em crise e, mais importante ainda, em que a crise económica põe em questão certos modelos de crescimento e de desenvolvimento industrial, marcados pelo crescente desemprego, em que os países capitalistas se vêem a braços com uma crise social e económica só comparável à que se viveu nos anos trinta - viverem, neste final do século, aquilo a que alguns já chamaram os seus dias de glória. Independentemente de qualquer reflexão, o que ninguém pode negar é que todo o imaginário em torno da empresa - a qual tem agora uma função social importante, é vista como indispensável para o desenvolvimento económico das regiões e dos países, apresenta-se agora como um espaço de harmonização e de realização pessoal imprescindíveis - mudou profundamente. Tida, até há bem pouco, como um mal necessário, somente tolerada, mais temida que amada, a empresa e os empresários têm assistido a movimentos de opinião favoráveis que alguns autores não enjeitam afirmar, com destaque, que finalmente a empresa se reconciliou com o público ${ }^{13}$. A prova, do que acabamos de referir, está no facto de já nos parecerem comuns os discursos que defendem, por exemplo, que os partidos políticos, as universidades, os clubes desportivos e associações, etc. devem proceder e organizar-se como empresas. E, por outro lado, começa mesmo a ser banal o facto de vermos empresários e altos quadros das empresas emergirem como importantes fenómenos mediáticos, ofuscando, por vezes, altas figuras dos governos nacionais. $\mathrm{E}$, talvez mais grave, começamos mesmo a não dar conta de repetirmos comportamentos, tiques, maneiras que nos vêm por via de uma cada vez maior massificação de uma cultura empresarial que se transformou numa das mais importantes ideologias da nossa modernidade. Do facto em si não resulta mal algum - é um fenómeno cultural igual a tantos outros na história -, mas já me parece preocupante se não tivermos consciência dele e nos deixarmos conduzir acriticamente pelo seu efeito moda.

Esta sacralização das empresas e do espírito empresarial tem vindo a ser objecto de alguma reflexão e crítica, por parte de autores que recusam a mitificação da empresa e o crescente domínio daquilo que rotulam de ideologia empresarial. Saliente-se, neste sentido, a recente obra de Jean-Pierre Le Goff, Le mythe de l'entreprise, que, partindo da análise crítica de textos ligados às empresas - regulamentos e projectos de empresa - , pretende mostrar que a ideologia que lhes está subjacente não só não previne a eficácia das organizações, como acaba por assentar na manipulação dos indivíduos (J. P. Le Goff, 1992). Na opinião deste autor, a empresa apresenta-se hoje — depois de tantos anos de contestação social - como modelo de sociedade e pretende fazer passar um discurso de reconciliação dos homens. E, deste modo, procura chamar a si valores culturais e éticos 
até há bem pouco fora dos seus horizontes. Ao chamar a si esta responsabilidade social, questiona o referido autor, não estará a empresa a «tirar lucro da crise de modos anteriores de aç̧ão colectiva»? (Idem: 278). Pois, numa sociedade em crise de referências comuns, não deixa de ser curioso que sejam as teorias ligadas às empresas a assumir o papel de defensoras dos valores humanistas esquecidos.

A crer nos modernos discursos empresariais, a natureza das empresas mudou profundamente. Ao modelo de organização tayloriana, que tinha sobretudo uma finalidade económica, sucedeu um outro que aposta na reconciliação harmoniosa do homem com a produção. É, portanto, como sublinha P. Le Goff, o retorno da moral à empresa numa altura em que os seus tradicionais defensores - Igreja, Estado, Família, Escola —são contestados e perdem autoridade (Idem: 203). Contudo, o perigo vem da tentação, hoje evidente, de a empresa tentar preencher o vazio deixado por estas instituições - é notória a tentativa de a empresa se afirmar «como o pólo de excelência em todos os domínios» e proclamar «alto e forte a sua missão social e cultural», pois, como cidadã, «exige a sua parte de responsabilidade nas tarefas da cidade» (Idem:11) —, acabando por criar a ideia de que para além delas e daquilo que é bom para as organizaçoes nada interessa.

Curiosamente, o autor que temos vindo a citar encontra na ideologia empresarial moderna motivações muito semelhantes às de Saint-Simon (1760-1825) nos inícios da industrialização. Hoje, diz Le Goff, «A ideologia do empresário anuncia a reconciliação dos homens dentro da empresa moderna. Ela emerge como o pólo da sociedade, e as outras actividades deveriam, a partir de agora, colocar-se ao seu serviço» (Idem: 206). Ora, sem o saberem, os empresários modernos retomam o essencial «da utopia saint-simoniana que foi gerada com o nascimento da indústria e acompanhou o seu desenvolvimento» (Idem). Também a utopia industrialista de Saint-Simon, refere ainda o mesmo autor, pretendia «acabar com a dominação e mobilizar os indivíduos e a sociedade toda para a produção» (Idem).

Concorde-se ou não com esta tese, a verdade é que na década de oitenta tem-se vindo a acentuar, no discurso político dominante, uma tendência para ver nas empresas a resolução de todos os problemas com que se deparam os países. Tendência que se torna cada vez mais evidente à medida que os governos nacionais vão ficando mais impotentes para estancar politicamente a crise social e, sobretudo, o desemprego. Situação que ainda leva mais à centração nas empresas e a ver na economia o remédio para todos os problemas.

Esta visão economicista das coisas, bem como a ameaça que advém da subordinação da cultura e da política ao chamado espírito empresarial - que, no fim de contas, está subjacente à ideologia empresarial moderna - apresenta perigos evidentes. Vejamos o que a este respeito diz Le Goff:

"A ideologia empresarial apresenta-se sob um duplo aspecto de eficácia e de ética: ela pretende responder por um lado às exigências da economia moderna $\mathrm{e}$ fazer da empresa o novo lugar que dará o sentido que falta à sociedade» (Idem: 
279). Ora, este protagonismo social da empresa só se compreende, como temos vindo a referir, à luz de uma crise acentuada dos modelos culturais, políticos e ideológicos tradicionais e à tendência clara para a dominação do discurso marcadamente economicista que, no fim de contas, tem impedido um debate político mais profundo e noutro sentido. Insistir, portanto, nesta utopia de colocar na empresa a responsabilidade da solução de todo um conjunto de problemas que, tradicionalmente, não lhe estavam confiados, pode ajudar de momento a legitimar as organizações produtivas e a estabelecer a tão ansiada reconciliação com o público - aliviando por outro lado o Estado das suas obrigações sociais - mas, a breve prazo, serão as próprias empresas a sofrer com as consequências de uma utopia que não corresponde aos anseios dos que nela acreditaram. As empresas são, nas sociedades contemporâneas, peças fundamentais para a criação de riqueza e para o desenvolvimento económico das nações. Todavia, o seu discurso peca por, paradoxalmente, fazer a apologia do individualismo e da autonomia individual, ao mesmo tempo que propõe aos seus colaboradores que se dissolvam na comunidade da empresa. Parecendo dar razão aos que afirmam que o novo discurso da gestão moderna está longe de romper com o paradigma de gestão tradicional. E tudo porque continua a querer branquear a diferença e o conflito existentes nas organizações e a escorar toda a sua fundamentação teórica e prática, como adverte Michel Debay, na «não-contradição e a anestesiar-se numa regulação hiper-realista» ${ }^{14}$.

\section{A EMERGÊNCIA DA CULTURA DE EMPRESA}

Vimos anteriormente que a empresa conseguiu, nos últimos anos, uma legitimidade nunca antes alcançada. As organizações produtivas pretendem, agora, ser vistas como um lugar onde se geram consensos e como um importante pólo de realização do indivíduo. Ora, a emergência da apreensão dos ambientes organizacionais como culturas aparece profundamente ligada a este novo discurso e imagem da empresa.

Não vamos aqui referir o enorme leque de factores que condicionaram essa emergência (económicos, sociais, culturais, ideológicos, epistemológicos, etc.). Gostaríamos, no entanto, de corroborar a opinião de Félix Torres quando vê nesta confluência, por parte de dois universos até aqui bastante afastados, uma manifestação de procura de legitimidade social por parte das organizações, numa altura em que cresciam os discursos que a punham em causa: «Tomada à letra - diz o referido autor - a noção de cultura de empresa veicula o contrário daquilo que enuncia: não a abundância de valores reconhecidos, mas pelo contrário o défice provisório deles, défice reconhecido como tal, o que levou à necessidade de o combater» ${ }^{15}$. 
Teriam sido, portanto, a necessidade de responder a esta contestação, por um lado, e o sentimento de que as tradicionais formas de gestão - o exemplo japonês foi marcante neste sentido - já não respondiam às novas realidades sociais e económicas da modernidade, por outro lado, que acabaram por conduzir à valorização de aspectos até aí arredados das teorias de gestão. É um fenómeno de crise de legitimidade, sem dúvida, que acaba por pressionar a empresa no sentido da cultura e das ciências sociais até aqui pouco familiarizadas com as organizações. $E$ isto precisamente, por mais paradoxal que pareça, numa altura em que a cultura revolucionária e operária e o marxismo perderam parte do seu vigor, como discurso ideológico de contestação no seio das empresas. Razão pela qual, muitos autores são levados a crer que o facto de os mais graves conflitos sociais, desta última década, não terem como centro a empresa, por um lado, e a nova realidade social no interior das empresas ter vindo progressivamente a substituir a tradicional luta de classses por um complexo jogo de poderes dentro da empresa, por outro lado, é que teriam levado à mudança de métodos de investigação da empresa, por parte de um conjunto de ciências e investigadores, até aqui muito pouco sensibilizados para fazerem da organização um objecto de estudo autónomo e privilegiado. Situação que conduziu a uma substancial mudança de atitude epistemológica e metodológica - dos estudos exteriores e de um ponto de vista estrutural, passou a privilegiar-se a investigação e os estudos dentro da empresa - que não deve ser secundarizada na análise, quer da nova ideologia empresarial, quer dos factores que mais directamente influenciaram a emergência da perspectiva cultural das organizações. Queremos com isto dizer que os investigadores foram atrás da conjuntura ${ }^{16} \mathrm{e}$ acabaram por ser instrumentos de legitimação de um novo discurso sobre as empresas? Claro que não. Queremos apenas referir que tal como não se concebe, hoje, uma ciência que separe o sujeito que explica do objecto a explicar, também não podemos deixar de admitir que o aumento vertiginoso, sobretudo no âmbito das ciências sociais, da literatura científica sobre as organizações, não pode deixar de ser vista como, ao mesmo tempo, agente e reflexo do lugar central que é hoje atribuído à empresa, aos empresários e à cultura empresarial.

A empresa teve, portanto, necesidade de encontrar novos modelos de gestão, com capacidade de resposta aos novos desafios. A cultura de empresa - quer a entendamos como moda, quer a vejamos como uma nova ideologia e como metáfora do poder, ou, ainda, como uma metáfora que permitiu aumentar a inteligibilidade das organizações, ou mesmo como uma verdadeira ruptura com os paradigmas de gestão anteriores - representa essa tentativa de resposta e é, já hoje, um dos fenómenos mais interessantes, independentemente dos juízos que se façam, da história das organizações. $O$ sucesso deste conceito, a nível dos países mais industrializados, é de tal monta que Maurice Thévenet, no seu livro Audit de 
nos E.U.A., mais de 50\% das intervenções se debruçaram sobre a cultura de empresa (M. Thévenet, 1986:23). Razão pela qual se torna muito difícil hoje definir com exactidão toda a realidade que o conceito envolve. Definido por $E$. Schein como «um conjunto de valores, de crenças e de normas que um grupo adoptou para resolver os seu problemas de integração internos e adaptação ao meio» (E.Shein, 1985), o conceito de cultura de empresa tem vindo a ser objecto de inúmeros estudos, o que torna praticamente impossível prever onde nos pode levar esta problemática

Contudo, alguns autores têm vindo a chamar à atenção para a existência de duas correntes no seio desta abordagem cultural das organizações:

a) Uma mais teórica e académica, sobretudo virada para a procura de outras soluções capazes de substituir os anteriores paradigmas de gestão;

b) Uma outra produção teórica, sobretudo virada para a aplicação prática da cultura aos fundamentos de gestão tradicional, pouco interessada em romper com o anterior paradigma. (A. Lopes e L. Reto, 1990:31).

A. Lopes e L. Reto - no seu livro Identidade da Empresa e Gestão pela Cultura - fazem referência a um estudo que, após a análise dos conteúdos da literatura produzida sobre cultura de empresa, mostra o domínio claro do discurso dos práticos, sobre o discurso académico, sobretudo a partir de 1982. Ou seja: «A literatura produzida encaminhou-se progressivamente para o reforço da ideia de cultura enquanto controle, sendo significativa a quebra acentuada da defesa da cultura enquanto paradigma alternativo» (Idem). Ambas as vertentes, referem ainda os autores citados, «associam a gestão pela cultura à coesão e à lealdade, embora os discursos dos práticos coloquem mais ênfase na noção de que a cultura é uma variável que pode ser manipulada, e que esta manipulação está associada à integração social e ao aumento da eficácia e da produtividade» (Idem).

É evidente que o domínio desta vertente, mais manipulatória da cultura, acaba por dar razão aos que entendem que esta perspectiva cultural das organizações pretende apenas mudar a imagem das empresas, sem que, no fundo, elas mudem. Para estes, a metáfora cultural não passa de uma metáfora do poder. Não passando, portanto, de uma noção instrumental útil para a mobilização e «interiorização de normas decretadas pela direcções», socorrendo-se para isso da cultura como «técnica de manipulação dos indivíduos» (J. P. Le Goff, 1992:177).

Este domínio da cultura, enquanto controle, tem também vindo a ser criticado por alguns autores que, embora não ignorem os contributos trazidos pela abordagem cultural, pretendem dar-lhe uma outra direcção. Encontram-se neste caso os autores que em França têm vindo a preferir ao termo cultura o de identidade. 


\section{CULTURA DE EMPRESA E IDENTIDADE DE EMPRESA}

Algumas vezes utilizados como sinónimos, os conceitos de cultura de empresa e de identidade parecem tender a seguir caminhos teóricos e práticos diferentes. A cultura de empresa, é sabido, teve a sua origem e os maiores aprofundamentos teóricos em países anglo-saxónicos, sobretudo na América do Norte. Todavia, embora os franceses se tenham sempre mostrado, mesmo em termos de investigação, ciosos da sua cultura, não nos parece que tenha sido apenas por orgulho $e$ culto da originalidade que em França o conceito de identidade tem vindo a ganhar mais adeptos. A. Lopes e L. Reto mostraram já que os dois conceitos se separam pelas diferenças de enfoques: «associação da ideia de empresa com a da estrutura e do funcionamento psicológico do indivíduo - a identidade; ou a comparação da estrutura e do funcionamento da empresa com as particularidades dos esquemas culturais das sociedades - a gestão pela cultura» (A. Lopes e L. Reto, 1990:16). Contudo, se bem que esta seja uma diferença importante, algo de mais profundo, a nosso ver, divide as duas perspectivas. É que, para os defensores do conceito de identidade, a maioria das abordagens culturais mais não fazem do que contribuir para o refinamento das práticas tradicionais de gestão. $\mathrm{E}$ isto porque a denominada «corporate culture», ora dominante, contrariamente às perspectivas que pretendem romper com o modelo tradicional de gestão, percepciona as organizações como tendo uma cultura e não como sendo uma cultura. Razão pela qual, os defensores da referida «corporate culture» acabam por restringir as suas abordagens a formas de conhecer e mudar as culturas existentes, privilegiando, sobretudo, a perspectiva simbólica em detrimento das vertentes ideológicas e do poder.

Para os teóricos ligados ao conceito de identidade - saliente-se, nesta perspectiva, o contributo de R. Reitter e B. Ramanantsoa (1985) - as organizações são tidas como únicas, como entidades autónomas e singulares. Para eles, «a organização é composta de seres humanos, que têm uma certa presença, e a acção colectiva dentro da empresa encontra-se geralmente marcada por uma lógica coerente, que a destingue de todas as outras. Esta lógica constitui-se e afirma-se ao longo do tempo. Ela dá à empresa uma certa continuidade; ela permite a cada um identificar a empresa e, em certos casos, não se identificar com ela" (Anastassopoulos et al., 1991:401). Todavia, lembram ainda estes autores, a utilização de conceitos como «identidade colectiva» não «implica uma profissão de fé unanimista» (Idem: 403). Pois, ao contrário da metáfora cultural, o conceito de identidade percepciona a empresa como um «lugar de conflito, dado que não há uma empresa sem poder» (Idem). É por este facto, lembram, que este «conceito é mais pertinente do que a metáfora cultural, apesar de esta ser mais utilizada» (Idem). Esta caracteriza-se por ser «um conceito mais passivo - agora que se trata de procurar novas vias e a liberdade de agir - e também mais asséptico, logo mais 
manipulador» (Idem).Por outro lado, enquanto que a cultura «subsiste ao nível superficial, das ideias, dos valores ou das crenças, aquilo que é conveniente chamar de universo simbólico (as ideologias, mitos, ritos, tabus, normas de comportamento que eles exprimem), a identidade inscreve-se ao nível das paixões e dos fantasmas. A noção de identidade interroga-se sobre as modas de emergência destas imagens e destes símbolos; pois é lá que se encontra o verdadeiro problema do poder» (Idem). E os autores que temos vindo a referir vão mesmo mais longe, na apreciação daquilo que os distingue da cultura de empresa: «Ė preciso esforçarmo-nos a ultrapassar - sem o negar — os aspectos mais vulgarizados da cultura de empresa: os mitos não são mais que meios de realizar o consenso; os ritos organizam e hierarquizam tudo e tanto como divertem o observador exterior; quanto à ideologia, ela não é reservada senão para os outros» (Idem). Ora, o conceito de identidade pretende ir mais além, não se fica apenas pelo superficial e folclórico. Para isso, é preciso analisar, sem dúvida «os grandes textos fundadores da política de empresa, mas também a psicologia psicanalítica da organização» (Idem).

Assim, segundo a definição de B. Ramanantsoa - um dos principais teóricos deste conceito, como vimos - a identidade de empresa é constuída por duas vertentes principais: o imaginário e as produções simbólicas. $\mathrm{O}$ imaginário, por sua vez, é constituído por três vertentes principais:

a) a imagem que os trabalhadores têm da empresa;

b) a imagem que cada um tem das qualidades morais e profissionais da empresa;

c) a imagem dos grupos influentes internos e externos à empresa.

Em relação às produções simbólicas, $B$. Ramanantsoa realça os seguintes aspectos: discursos oficiais: ideologia, gestão do tempo e organização do espaço; as histórias sobre a organização; os mitos; os hábitos; ritos; e aquilo de que normalmente não se fala: os tabus ${ }^{17}$.

\section{Os Eixos Polarizadores da Identidade}

Num mundo em mudança acelerada, o problema da identidade tem todos os ingredientes para se tornar num dos temas mais úteis às organizações. Adequar as estratégias e políticas das empresas à identidade da organização emerge hoje como o mais importante valor acrescentado na concorrência entre as empresas. Num tempo em que a política de baixos custos já não dá os frutos de outrora, só as empresas que forem capazes de se encontrar e gerir a sua identidade têm possibilidade de vencer. Uma gestão somente virada para a racionalização dos custos e para as mudanças físicas (novas tecnologias, novos espaços, mais meios financeiros) facilmente pode ser imitada pela concorrência de outras empresas. 
O mesmo não acontece com empresas que se mostrem capazes de gerir e perceber a identidade da sua empresa.

Para uma melhor percepção da identidade, vários autores têm vindo ultimamente a desenvolver alguns modelos teóricos capazes de determinar com rigor os focos principais da identidade das empresas. Acabando por concluir que grande parte das organizações produtivas tendem a articular-se em torno daquilo que denominaram por «objecto principal de focalização». Definindo-se esta focalização da identidade «como um processo dinâmico para o qual as aspirações e as acções dos membros de uma mesma entidade económica e social convergem, constituindo assim a ossatura da identidade» (Anastassopoulos et al., 1991:449). Segundo estes autores, esta convergência pode exprimir-se de três formas diferentes:

a) focalizada num produto ou domínio de actividade;

b) focalizada em competências ou modos de comportamento que ligam todos os que aí trabalham;

c) focalizada num líder carismático, ou num conjunto de dirigentes no qual a empresa se reconhece.

Não escondem, no entanto, alguns autores que estes três casos de focalização apresentam em si forças e fraquezas: a focalização sobre o produto tem imensas vantagens quando se trata de desenvolver estratégias de especialização, todavia a sua principal fraqueza advém da pouca maleabilidade para desenvolver estratégias de diversificação de produtos e actividades; por sua vez, a focalização sobre o líder oferece vantagens evidentes num mundo de mudança e de constantes perturbações, mas tem o perigo de, após o desaparecimento do líder, ficar a organização presa e órfã de liderança e ser assim um forte bloqueio à inovação e a novas estratégias; por último, a focalização sobre os comportamentos é tida como muito aberta aos movimentos estratégicos, mas sofre da síndroma da inadaptação a fortes mudanças do meio envolvente à organização (Idem).

Para B. Ramanantsoa, «De uma forma geral nós podemos estabelecer uma relação entre identidade, tipo de poder e práticas de decisão. Assim, no caso de uma identidade focalizada sobre um líder carismático, o poder será concentrado sobre alguns indivíduos: o líder e sua "banda". No caso de uma identidade focalizada sobre o produto, nós podemos constatar que os dirigentes aparecem como guardiães da tradição e do respeito dado ao produto. Enfim, nas empresas focalizadas sobre os comportamentos procura-se privilegiar a eficácia económica, tudo o que aparece como um jogo político transforma-se em tabu» ${ }^{18}$.

Definido o conceito de identidade, vejamos agora como é que ele se relaciona com o discurso histórico e, sobretudo, qual o papel que ele representa na estruturação da identidade da empresa. 


\section{IDENTIDADE E HISTÓRIA}

Alain Plessis, referindo-se às novas relações entre a história e a empresa, escreveu: «Durante a década de 1980 uma nova via, particularmente sedutora, abriu-se aos historiadores, com a cultura de empresa» (A.Beltrane M. Ruffat, 1991:13). De facto assim acontece. E não se trata apenas, como refere o mesmo autor, de um «novo alimento para satisfazer o seu insaciável desejo de tratar todas as facetas do passado», a história pode ajudar «a um melhor conhecimento da identidade cultural» da empresa (Idem: 15). A investigação histórica - numa altura em que se sucedem as reestruturações e fusões de empresa, num tempo de mudanças rápidas nas estratégias, nos mercados, nos produtos e nas tecnologias - poderá ser o instrumento necessário no combate à ameaça de amnésia nas organizações. A perspectiva cultural das organizações é hoje responsável pela aceitação de que toda a empresa tem uma memória específica e que dentro dela há um saber acumulado que não pode ser destruído: Logo - lembra François Caron —, «Não há cultura de empresa séria sem história. Uma cultura de empresa que se queira a-histórica não poderá ganhar corpo» (Idem: 41). Contudo, alerta o mesmo autor, «esta história deve ser uma história sem concessões, que recuse a apologia, que não seja apenas uma simples distracção, mas uma história cientificamente conduzida». Deve-se, por isso, «desconfiar sempre de historias feitas à pressa, de histórias apologéticas, de histórias reduzidas a instrumentos de discursos publicitários» (Idem).

Esta nova perspectiva cultural das organizações coloca, como vimos, novas questões a ciências que, como é o caso da história, mantiveram com as empresas uma relação de conflitualidade. As razões deste conflito, contudo, não podem ser assacadas apenas a um dos lados. Pois, se os historiadores têm preferido estudar as empresas numa perspectiva macroeconómica, privilegiando a análise estrutural e a ligação da empresa à evolução do sistema capitalista, também os empresários e as ciências mais ligadas à gestão das empresas só agora começam a perceber a utilidade da história nas organizações (M. Hamon e Félix Torres, 1987: 7-9). Se os historiadores tardaram em compreender que cada história de empresa é um caso específico, os dirigentes de empresa ainda hoje vêem a história como um instrumento publicitário e apologético e, muitas vezes, como um entrave à própria modernização (Idem: 36 ).

Em face deste quadro, a história e os historiadores não podem continuar indiferentes. A questão que hoje se coloca - não é tanto a de inventariar os casos em que a história pode ser útil às empresas - é, sobretudo, a de procurar respostas teóricas e metodológicas que permitam aos historiadores dar o seu contributo na explicação e compreensão desta nova realidade. A história é a ciência mais bem colocada, pela sua sensibilidade em relação à mudança, para levar à compreensão do lugar central que a empresa hoje ocupa nas sociedades modernas, sem escamotear a perspectiva diacrónica. 
A verdade é que, queiram ou não os historiadores, a empresa é já hoje objecto privilegiado de um vasto conjunto de outras ciências sociais. Compete agora à história e aos historiadores mostrar em que medida o seu contributo, tanto a nível teórico como prático, pode ajudar ou não a compreender melhor as organizações e a torná-las mais humanas e competitivas.

Ninguém duvida hoje que a importância da história na empresa decorre da revalorização da cultura de empresa e do papel que a identidade representa, como recurso essencial para uma melhor e mais eficaz mobilização dos trabalhadores, em torno de um projecto comum. O discurso histórico aparece, assim, como um dos pilares da identidade. Não foi, portanto, «por acaso - referem os autores de Strategor - que numerosas empresas decidiram escrever [refere-se, obviamente, à realidade francesa que, como é sabido, não encontra ainda paralelo em Portugal] a sua história» (Anastassopoulos, 1991:461). A empresa «foi muitas vezes uma organização amnésica gerindo o quotidiano, deixando a história para os arquivos quando eles existiam»; só o reconhecimento de que a identidade de uma empresa era «o produto da sua história, desde os grandes actos fundadores que estiveram ligados à sua criação e desenvolvimento, até aos grandes momentos que acabaram por moldar um determinado estilo de vida, os seus hábitos e comportamentos, os seus mitos, os seus ritos e seus tabus», é que levou gestores e empresários a olhar a história com outros olhos (Idem).

Vejamos, então, que virtudes e poderes é que a história tem para que as portas das empresas - durante tanto tempo fechadas e, nalguns casos, como é o caso de Portugal, ainda entreabertas - lhe tenham franqueado a entrada.

\section{O(s) Poder(es) da História na Estruturação da Identidade}

Acabámos de ver que a valorização do conceito cultural e a necessidade de encontrar novas formas de gestão que ajudassem as empresas a responder melhor aos novos desafios, de um mundo mais concorrencial e mais exigente, do ponto de vista económico e social, acabou por valorizar novos conceitos e modos de encarar o ambiente organizacional. $O$ conceito de identidade e a necessidade de enraizamento histórico, por parte das empresas, estão intimamente ligados a este novo ambiente.

Importa, portanto, que aqui analisemos de forma mais detalhada, ainda que incompleta, como pode a história responder a esta nova realidade trazida pela metáfora cultural e, sobretudo, pelo conceito de identidade. Para um melhor entendimento, embora pensemos que na realidade isto não se verifica, passamos a analisar, separadamente, os três vectores fundamentais no processo de estruturação da identidade:

a) O discurso histórico como instrumento fundamental na interpretação do tempo: ligação do passado-presente-futuro; 
b) O discurso histórico como criador de sentimentos de pertença: símbolos, valores, mitos, etc.;

c) O discurso histórico como ideologia e como instrumento do poder.

Em relação à primeira alínea é importante dizer o seguinte: o discurso histórico é, por natureza, uma interpretação ou representação diacrónica - ou, embora mais raramente, sincrónica - do passado. Sensível às mudanças, a história ajuda a interpretar o tempo, ligando o passado ao presente e o presente ao passado, numa interaç̧ão constante, sem perder de vista o futuro. Ao proceder deste modo, a história não só legitima um determinado percurso colectivo das organizações, como reforça a noção de continuidade através do tempo. Compreender-se-á melhor a importância desta interpretação do tempo, para a estruturação da identidade, se tivermos em consideração que «é o tempo que permite - lembram os autores de Strategor - extrair a coerência do conjunto da organização, de a comparar com outras e de lhe conferir uma permanência. É o tempo que permite identificar uma empresa e, eventualmente, deixar de se identificar com ela ou, mesmo, rejeitá-la». Não custa, portanto, a entender o poder e a importância da história na estruturação da identidade, já que, lembram os autores referidos, a «identidade organizacional é um produto do tempo» (Anastassopoulos, 1991:457). ${ }^{19}$

Em relação à segunda alínea ocorre-nos dizer o seguinte: um maior e melhor conhecimento da história das empresas - dos seus fundadores, das suas crises e dos seus sucessos, da evolução e mudanças tecnológicas, etc. - acaba sempre por reforçar o sentimento de pertença à organização. Sabendo-se companheiros e herdeiros de um passado comum, partilhando, portanto, um imaginário específico, é natural que isto ajude a uma melhor identificação com a organização. $O$ papel da história acaba por ser mesmo o de (re)construir uma memória que «crisalizará as recordações e permitirá à empresa afirmar a sua identidade graças a este suplemento de alma que vem do passado sempre mais rico do que nós pensamos» (A.Beltran e M. Ruffat, 1991:30). Este poder da história em (re)construir a memória do passado - não forçosamente, é certo, de acordo com a memória dominante na organização- leva-nos ao terceiro ponto, por nós anteriormente enunciado: $o$ discurso histórico como ideologia e como instrumento do poder.

Todo e qualquer historiador sabe a importância que as imagens do passado assumem na legitimação de projectos políticos, quer do presente, quer do futuro. Dominar a memória colectiva - quer seja de uma nação, de um grupo, ou organização - é, conscientemente ou não, um objectivo e instrumento de todo o poder. Lembra Jacques Le Goff que «São as sociedades cuja memória social é sobretudo oral ou que estão em vias de construir uma memória colectiva escrita que melhor permitem compreender esta luta pela dominação da recordação e da tradição» (J. Le Goff, 1984:46).

Não admira, assim, que os defensores do conceito de identidade - mais preocupados em interrogar-se sobre os modos de emergência das imagens e dos 
bolos e com as fontes do(s) poder(es) dentro da empresa - incluam a história no campo das produções simbólicas (ao lado dos discursos oficiais, da ideologia, dos mitos, dos ritos, etc.) e a definam como uma das ideologias ligadas ao poder e às práticas de decisão. A este propósito, escreveu B. Ramanantsoa: «se aceitarmos a definição segundo a qual a ideologia é um discurso sobre a acção política, acabamos por compreender que a história de empresa e sobretudo a história $n a$ empresa corresponde a esta definição» ${ }^{20}$. Ainda que se aceite que esta visão de B. Ramanantsoa é demasiado simplista e redutora, sobretudo porque não tem em conta a capacidade problematizadora que o actual discurso histórico tem, não podemos deixar de concordar com ela.

A história não pode, assim, deixar de ser vista — residem aqui os seus poderes - enquanto importante pilar da identidade de empresa e como instrumento do poder de quem dirige. $O$ seu discurso não pode fugir - independentemente da vontade de quem o elabora:o historiador - a ser utilizado como justificação da estratégia e política de empresa. $\mathrm{E}$, assim, funcionando como qualquer ideologia, estrutura a identidade da organização ao mesmo tempo que ajuda a dar um sentido à aç̧ão colectiva. Mas os poderes da história, como lembra B. Ramanatsoa, não se ficam por aqui: « ela pode também ocultar a realidade, quer dizer o mercado e a concorrência». E por isso, corroborando o desejo do autor citado, é preciso «também evitar que a história se transforme no mais perigoso produto químico que alguma vez o nosso intelecto elaborou $»^{21}$.

\section{CONCLUSÃO}

A primeira conclusão a retirar de tudo o que dissemos é a de que os historiadores se arriscam, por culpa própria, a entrar num debate, em torno das organizações, como auxiliares de outras ciências sociais. Até agora, foram ciências como a sociologia, a antropologia e a psicologia, entre outras, que conduziram e abriram as organizações a outras perspectivas e outros entendimentos. Razão pela qual, à história tem cabido o secundaríssimo papel de ajudante de serviço de modelos e interpretações iniciados por outros. Não se trata aqui de qualquer concorrência ou luta entre ciências, pelo domínio de determinados objectos - neste caso das organizações - trata-se, isso sim, de constatar que é notória neste debate a falta de uma ciência que o coloque numa perspectiva diacrónica e que estabeleça a relação dialéctica entre o imaginário e as ideologias empresarias do passado e do presente.

Para fugir a esta quase fatalidade, cabe aos historiadores - sem que para isso tenham de deixar de ter em conta os contributos das outras ciências - encarar a empresa, embora de acordo com os seus métodos, de uma forma original. Ou seja:

112 se a cultura de empresa abriu as organizações a novos entendimentos, a história 
não se pode limitar a estudar a empresa através dos caminhos abertos e trilhados pelas outras ciências. Exige-se-lhe que crie os seus próprios conceitos e percorra um caminho próprio, sem que para isso tenha de perder a sua qualidade de ciência aberta a outras àreas do saber. Não importa apenas que se repita que não existe identidade ou cultura de empresa sem história, é preciso que a história faça a abordagem cultural das organizações segundo modelos e conceitos próprios.

\section{NOTAS}

1. Tradução minha, como em casos análogos, de citações a partir de língua estrangeira.

2. Henri Weber, «Notre pére qui êtes au $26^{e}$ étage.», Autrement (número monográfico, sob o título Le Culte de l'entreprise - Mutations, Valeurs, Cultures), $\mathrm{n} .^{\circ}$ 100-Septembre, 1988, p. 59.

3. Idem, ibidem.

4. Bernard Ramanantsoa, «Identité d'entreprise et décision: les contraintes de l'histoire», in Memoire d'avenir - L'histoire dans l'entreprise (Dir. Maurice Hamon e Félix Torres), Paris, Ed. Economica, 1987,p. 155.

5. Sobre esta perspectiva da história como instrumento do poder, cf. idem, ibidem, pp. 145-161.

6. Idem, ibidem, p. 153.

7. Idem, ibidem.

8. Sobre este aspecto, cf. Lévi-Strauss, Mito e significado, Lisboa, Ed.70, 1984, pp. 54-64.

9. Bernard Ramanantsoa, ob. cit., pp. 151-152.

10. Vejam-se, entre outros trabalhos deste autor, Santos Barosa - 100 anos do vidro, Marinha Grande, Ed. de Santos Barosa - Vidros, SA, 1992, «A história na empresa e a empresa na história» ( no prelo, a publicar num vol. de homenagem ao Prof. J. Borges de Macedo) e «Cultura de Empresa: uma nova dinâmica organizacional», Gestão e Desenvolvimento, 1 (1992), pp. 49-57.

11. José Amado Mendes, «A História na empresa e a empresa na historia».

12. Idem, ibidem.

13. É este o sentido de um artigo de Jean Auroux ao afirmar: «Após uma longa hesitação, à semelhança de outros povos economicamente desenvolvidos, os franceses deram um salto e começam a viver a fase dois. Isto não $\mathrm{e}$ em si mau, a partir daqui os franceses reconciliaram-se com as empresas» (Jean Auroux), «Rêve de flexible», Autrement (número monografico, sob o título Le culte de l'entreprise - mutations, valeurs, cultures), n. ${ }^{\circ} 100-$ Septembre, 1988, p. 215.

14. Michel Debay, «La Duperie», Idem, p. 97. 
15. Félix Torres, «L'Entreprise Post-Modern», Idem, p. 23.

16. Sobre esta problemática, nomeadamente no que concerne ao papel dos investigadores, naquilo que podemos chamar de revalorização das empresas e dos empresários, ver Alain Etchegoyen, «À La recherche des savoires perdus», Idem, pp. 67-74.

17. Cf. Bernard Ramanantsoa, art. cit., pp.145-146.

18. Idem, ibidem, p.151.

19. Os autores citados não deixam, a propósito da importância desta dimensão histórica, de ilustrar as afirmações com o seguinte exemplo: «A Sony proclama uma parte da sua identidade pelo slogan «é novo, é sony», este símbolo não teria qualquer sentido se não se escorasse numa longa história» (Anastassopoulos, 1991: 458).

20. Bernard Ramanantsoa, art. cit., p.153.

21. Idem, ibidem, p.155.

\section{BIBLIOGRAFIA}

ANASTASSOPOULOS, Jean-Pierre, 1991, Stratégie, structure,décision, identité - Politique général d'entreprise, Paris, Inter Éditions.

AUROUX, Jean, 1988, «Rêve de flexible», Autrement, n. ${ }^{\circ}$ 100, pp. 214-217.

BELTRAN, Alain e RUFFAT, Michèle, 1991, Culture d'entreprise et histoire, Paris, Les Éditions d'Organisation.

DEBAY, Michel, 1988, «La Duperie», Autrement, n. ${ }^{\circ} 100$, pp. 93-97.

ETCHEGOYEN, Alain, 1988, «Á la recherche des savoires perdus», Autrement, n. ${ }^{\circ} 100$, pp. 67-74.

HAMON, Maurice e TORRES, Félix,1987, Mémoire d'avenir - L'histoire dans l'entreprise, Paris, Ed. Economica.

LE GOFF, Jacques, 1984, «Memória», Enciclopédia Einaudi - Memória História, 1, Imprensa Nacional-Casa da Moeda.

LE GOFF, Jean-Pierre, 1992, Le myte de l'entreprise - Critique de l'ideologie managériale, Paris, Editions la Découvert.

LOPES, Albino e RETO, Luís, 1990, Identidade da empresa e gestão pela cultura, Lisboa, Ed. Sílabo.

MENDES, J. M. Amado (col. de Manuel Ferreira Rodrigues), 1992, Santos Barosa - 100 anos no vidro, 1889-1989, Marinha Grande, Santos Barosa - Vidros, S. A.

MENDES, J. M. Amado, «Cultura de empresa: uma nova dinâmica organizacional», 1992, Gestão e Desenvolvimento, 1 , pp. 49-57. 
OLINS, Wally, 1991, Identité d'entreprise. Pour rendre la stratégie d'entreprise visible (trad. do inglês), Paris, Inter Éditions.

REITTER, Roland e RAMANANTSOA, Bernard, 1985, Pouvoir et politique - Au-delà de la culture d'entreprise, Paris, Mcgraw-Hill.

ROSA, Luís, 1992, Sociologia de empresa - Mudança e conflito, Lisboa, Editorial Presença.

STRAUSS-Lévi, 1984, Mito e significado, Lisboa, Ed. 70.

THÉVENET, Maurice, 1986, Audit de la culture d'entreprise, Paris, Les Éd. d'Organisation.

TORRES, Félix, 1988, «L'Entreprise Post-Modern», Autrement, n. ${ }^{\circ} 100$, pp. 22-27.

VALA, Jorge; MONTEIRO, M. Benedicta e LIMA, M. Luísa, 1988, «Culturas organizacionais — uma metáfora à procura de teorias», Análise Social, Vol. XXIV (101-102), pp. 663-687

WEBER, Henri, 1988, «Notre pére qui êtes au 26 e étage...», Autrement, n. ${ }^{\circ} 100$, pp. 55-59. 